The expression of Toll-like receptor 4, 7 and co-receptors in neurochemical sub-populations of rat trigeminal ganglion sensory neurons

Helley, MP

http://hdl.handle.net/10026.1/8606

10.1016/j.neuroscience.2015.09.069

Neuroscience

Elsevier BV

All content in PEARL is protected by copyright law. Author manuscripts are made available in accordance with publisher policies. Please cite only the published version using the details provided on the item record or document. In the absence of an open licence (e.g. Creative Commons), permissions for further reuse of content should be sought from the publisher or author. 


\section{THE EXPRESSION OF TOLL-LIKE RECEPTOR 4, 7 AND CO-RECEPTORS IN NEUROCHEMICAL SUB-POPULATIONS OF RAT TRIGEMINAL GANGLION SENSORY NEURONS}

\author{
M. P. HELLEY, ${ }^{a}$ W. ABATE, ${ }^{b}$ S. K. JACKSON, ${ }^{b}$ \\ J. H. BENNETT ${ }^{a}$ AND S. W. N. THOMPSON ${ }^{\text {** }}$ \\ a School of Dentistry, Plymouth University Peninsula Schools \\ of Medicine \& Dentistry, Plymouth University, Plymouth, Devon \\ PL4 8AA, UK \\ ${ }^{\mathrm{b}}$ School of Biomedical \& Healthcare Science, Plymouth University \\ Peninsula Schools of Medicine \& Dentistry, Plymouth University, \\ Plymouth, Devon PL4 8AA, UK
}

\begin{abstract}
The recent discovery that mammalian nociceptors express Toll-like receptors (TLRs) has raised the possibility that these cells directly detect and respond to pathogens with implications for either direct nociceptor activation or sensitization. A range of neuronal TLRs have been identified, however a detailed description regarding the distribution of expression of these receptors within sub-populations of sensory neurons is lacking. There is also some debate as to the composition of the TLR4 receptor complex on sensory neurons. Here we use a range of techniques to quantify the expression of TLR4, TLR7 and some associated molecules within neurochemically-identified sub-populations of trigeminal (TG) and dorsal root (DRG) ganglion sensory neurons. We also detail the pattern of expression and co-expression of two isoforms of lysophosphatidylcholine acyltransferase (LPCAT), a phospholipid remodeling enzyme previously shown to be involved in the lipopolysaccharide-dependent TLR4 response in monocytes, within sensory ganglia. Immunohistochemistry shows that both TLR4 and TLR7 preferentially co-localize with transient receptor potential vallinoid 1 (TRPV1) and purinergic receptor P2X ligand-gated ion channel 3 (P2X3), markers of nociceptor populations, within both TG and DRG. A gene expression profile shows that TG sensory neurons express a range of TLR-associated molecules. LPCAT1 is expressed by a proportion of both nociceptors and non-nociceptive neurons. LPCAT2 immunostaining is absent from neuronal profiles within both TG and DRG and is confined to non-neuronal cell types under
\end{abstract}

\footnotetext{
${ }^{*}$ Corresponding author. Tel: +44-1752584652.

E-mail address: stephen.thompson@plymouth.ac.uk (S. W. N. Thompson).

Abbreviations: AF, alexa-fluor; DAMP, damage-associated molecular pattern; DAPI, 4',6-diamidino-2-phenylindole; DRG, dorsal root ganglion; GAPDH, glyceraldehyde 3-phosphate dehydrogenase; IHC, immunohistochemistry; IL-1 $\beta$, Interleukin-1 $\beta$; LPS, lipopolysaccharide; LPCAT, lysophosphatidylcholine acyltransferase; MD, myeloid differentiation protein; mRNA, messenger ribonucleic acid; MyD88, myeloid differentiation primary response protein 88; NF200, neurofilament 200; P2X3, purinergic receptor P2X ligand-gated ion channel 3; PBS, phosphate-buffered saline; $\mathrm{QPCR}$, real-time polymerase chain reaction; RP105, radioprotective 105; TG, trigeminal ganglion; TLR, Toll-like receptor; TRAM, TRIF-related adapter molecule; TRPV1, transient receptor potential vallinoid 1 .
}

naïve conditions. Together, our results show that nociceptors express the molecular machinery required to directly respond to pathogenic challenge independently from the innate immune system. (C) 2015 IBRO. Published by Elsevier Ltd. All rights reserved.

Key words: pain, cell signaling, sensory neuron, trigeminal ganglion, dorsal root ganglion, Toll-like receptor.

\section{INTRODUCTION}

Traditionally it is thought that pathogens interact with sensory neurons through indirect mechanisms involving the activation of an innate immune response and production of pro-inflammatory mediators (see Ren and Dubner, 2010 for review). These indirect mechanisms involve the release of inflammatory mediators and the peripheral sensitization of high-threshold sensory neurons, nociceptors, increasing excitability to threshold and sub-threshold stimuli and contributing toward the transition from acute to chronic pain states (for reviews see Marchand et al., 2005; Ren and Dubner, 2010). A complex web of interactions between neurons, nonneuronal cells and immune cells develops to maintain a state of pain hypersensitivity (Milligan and Watkins, 2009; Austin and Moalem-Taylor, 2010; Grace et al., 2011; Nicotra et al., 2012). Previous work on the impact of inflammatory mediators on nociceptor sensitization and pain generation has suggested that the degree of pain associated with infection is heavily influenced by the degree of immune activation (Marchand et al., 2005; Ren and Dubner, 2010). It is now understood that sensory neurons can directly detect and respond to pathogenic challenge independent of the innate immune system.

Toll-like receptors (TLRs) are a family of innate pattern recognition receptors that detect a wide range of exogenous pathogenic and endogenous damagereleased ligands. Since the discovery by Wadachi and Hargreaves (2006) of TLR4 expression on trigeminal sensory neurons, a range of functional TLRs have been shown to be expressed by neurons in both the peripheral and central nervous system (Lafon et al., 2006; Mishra et al., 2006; Wadachi and Hargreaves, 2006; Cameron et al., 2007; Acosta and Davies, 2008; Barajon et al., 2009; Ochoa-Cortes et al., 2010; Diogenes et al., 2011; Ferraz et al., 2011; Qi et al., 2011; Due et al., 2012; 
Park et al., 2014; Tse et al., 2014a). The expression of TLRs in neurons, particularly primary sensory neurons, has uncovered a potential innate surveillance function with implications for both the acute nociceptive response and the maintenance of chronic pain states.

TLR4 and the co-receptor CD14 are expressed on rat and human transient receptor potential vanilloid 1 (TRPV1)-positive and TRPV1-negative nociceptors within the trigeminal ganglion (TG) (Wadachi and Hargreaves, 2006; Diogenes et al., 2011). Activation of TLR4, by Porphyromonas gingivalis lipopolysaccharide (LPS), on TG sensory neurons both sensitizes TRPV1 and potentiates capsaicin-induced calcitonin generelated peptide (CGRP) release (Diogenes et al., 2011; Ferraz et al., 2011). A role for TLR4, expressed by TG neurons, in mediating pain induced by tissue damage has also been demonstrated (Ohara et al., 2013; Miller et al., 2014). The activation of TLR4, by Escherichia coli LPS, on murine dorsal root ganglion (DRG) neurons has been shown to increase neuronal excitability (OchoaCortes et al., 2010; Due et al., 2012), nociceptin expression (Acosta and Davies, 2008) and the myeloid differentiation primary response protein 88 (MyD88)dependent production of pro-inflammatory mediators (Ochoa-Cortes et al., 2010; Tse et al., 2014a). The ability of TLRs to influence the nociceptive response is not limited to TLR4. Activation of TLR3, 7 and 9 expressed by DRG neurons induces the production of proinflammatory mediators, up-regulates TRPV1 expression and sensitizes TRPV1 activation (Qi et al., 2011). Activation of TLR3 and TLR7 induces an itch response (pruritus) and directly activates DRG nociceptors (Liu et al., 2010, 2012). More recently the activation of TLR7, by endogenous microRNAs, has been shown to rapidly activate DRG neurons through mechanisms that involve TRPA1 (Park et al., 2014).

In the DRG, the reported percentage of total TLR4positive neurons varies widely (28-60\%; Acosta and Davies, 2008; Due et al., 2012; Tse et al., 2014a,b). While it has been shown that $19 \%$ of neurons in the maxillary region of the TG and $29 \%$ of neurons innervating the gingivomucosa express TLR4, mainly in small- to mediumsized neurons (Vindis et al., 2014), there are currently no quantitative data for TLR4 expression within the TG as a whole. Previous studies have suggested that the expression of TLR7 is limited to small/medium sized neurons that express TRPV1 and TRPA1 although no quantitative analysis has been performed (Liu et al., 2010; Qi et al., 2011; Park et al., 2014).

There is also some debate regarding the composition of the TLR4 receptor complex expressed by sensory neurons. In innate immune cells a functional TLR4signaling complex consists of TLR4, CD14 and myeloid differentiation protein (MD)-2 (Akira and Takeda, 2004). DRG neurons reportedly express CD14 and MD-1 messenger ribonucleic acid (mRNA) and protein but little MD-2 and no radioprotective 105 (RP105) mRNA or protein (Acosta and Davies, 2008). Upon activation, neuronal TLR4 is reported to form an atypical co-receptor complex with CD-14 and MD-1 (Acosta and Davies, 2008). MD-1 classically interacts with the TLR4 homolog,
RP105 to regulate TLR4 signaling (Ohto et al., 2011). More recent studies however have shown that DRG neurons do express MD-2 and RP105 mRNA and protein in addition to MD-1 and CD14 mRNA and protein (OchoaCortes et al., 2010; Tse et al., 2014a). Additionally it was shown that the majority of TLR4-positive neurons co-localize with CD14 and MD-2, rather than MD-1 (Tse et al., 2014a).

Lysophosphatidylcholine acyltransferase 1 and 2 (LPCAT1 and LPCAT2) are two isoforms of a phospholipid-modifying enzyme that participate in membrane remodeling by mediating the acylation of lysophosphatidylcholine (see Shindou and Shimizu, 2009). The phospholipid/lysophospholipid composition of cellular membranes affects membrane function, including lipid raft functions (Stulnig et al., 2001), and therefore may impact upon multiple cellular signaling pathways including TLR4 signaling (see Triantafilou et al., 2011). In macrophages, LPCAT2 is activated by phosphorylation following TLR4-dependent LPS recognition (Morimoto et al., 2010) and LPCAT activity is essential for the translocation of TLR4 to lipid rafts and subsequent generation of a TLR4 signaling response (Jackson et al., 2008). LPCAT1 and LPCAT2 have been identified in a range of tissues although a high level of expression has been demonstrated in lung alveolar cells and immune cells for LPCAT1 and LPCAT2, respectively (Nakanishi et al., 2006; Shindou et al., 2007; Morimoto et al., 2010). Both LPCAT1 and LPCAT2 expression have been demonstrated in a sub-set of spinal neurons (Okubo et al., 2012). Whereas LPCAT1 expression is constitutive, LPCAT2 is an inducible form of the enzyme (Shindou et al., 2005). Indeed, LPCAT2 is up-regulated in microglia following nerve injury while LPCAT1 expression remains unchanged (Okubo et al., 2012). LPCAT2 expression has also been identified in peripheral sensory neurons as well as non-neuronal cells within the DRG following nerve injury (Hasegawa et al., 2010). While previous studies have identified the expression of LPCAT isoforms in injured DRG neurons, the expression of LPCATs naïve peripheral sensory neurons and the subsequent role they might play in the neuronal TLR response is unknown.

While it has been shown that nociceptors express a range of TLRs, a detailed analysis of TLR expression within multiple sensory neuron sub-populations has not been performed, particularly within the TG. A detailed analysis of TLR4 and TLR7 expression patterns within primary sensory neurons is a pre-requisite for further functional analysis of receptor activation. In the current study we explore the hypothesis that nociceptors possess the required molecular components to directly detect and respond to ligands of bacterial, viral and endogenous origin. Using well-defined neurochemical markers, we provide a semi-quantitative analysis of the expression of TLR4 and TLR7 within sensory neuron sub-populations. We also detail a gene expression profile of TLR signaling-associated components within the TG. Lastly, we describe the distribution of expression of two isoforms of a lysophosphatidylcholine acyltransferase (LPCAT) enzyme, LPCAT1 and LPCAT2 within sensory ganglia. 


\section{EXPERIMENTAL PROCEDURES}

\section{Materials}

All materials, unless otherwise stated, were purchased from Sigma-Aldrich (Gillingham, UK). All real-time polymerase chain reaction (qPCR) reagents were purchased from Life Technologies (Carlsbad, CA, USA).

\section{Animal care}

Age-matched, adult male Sprague-Dawley rats ( $>3$ months of age, 250-350 g, Charles River, UK) were group-housed in a temperature and humiditycontrolled environment with a 12-h light/dark cycle (lights on at 8:00 A.M.) with food and water available ad libitum. All experiments adhered to guidelines described by Schedule 1 of the UK 1986 Animals (Scientific Procedures) Act. A total number of 6 animals were used in this study: 3 for TLR and LPCAT immunohistochemistry and 3 for qPCR analysis of TLRassociated gene expression.

\section{Immunohistochemistry}

Indirect single- and dual-labeled immunohistochemistry (IHC) was performed to determine the distribution of expression of TLR4, TLR7, LPCAT1 and LPCAT2 and their co-expression with the functional neurochemical markers neurofilament 200 (NF200), thermo-transducer TRPV1 and purinergic receptor P2X3 in the rat TG and DRG. Adult male Sprague-Dawley rats were euthanized with a lethal dose of sodium pentobarbital $(100 \mathrm{mg} / \mathrm{kg})$ and animals were confirmed as being dead by confirming the permanent cessation of the circulation. Animals were then transcardially perfused with $0.1 \mathrm{M}$ phosphate-buffered saline (PBS, $\mathrm{pH} 7.4$ ) followed by $4 \%$ paraformaldehyde in $0.1 \mathrm{M}$ phosphate buffer $(\mathrm{pH} 7.4)$. TG, L4/L5 DRG, lung and spleen tissues were rapidly removed and post-fixed in $4 \%$ paraformaldehyde $(\mathrm{pH}$ 7.4) for $2 \mathrm{~h}$ at $4{ }^{\circ} \mathrm{C}$ then cryoprotected overnight in $20 \%$ sucrose in $0.1 \mathrm{M}$ phosphate buffer $(\mathrm{pH} 7.4)$ at $4{ }^{\circ} \mathrm{C}$. Tissue samples were snap-frozen in optimal cutting temperature compound (Tissue Tek, UK) and sequentially cryo-sectioned at $9 \mu \mathrm{m}$ (CM1100, Leica Biosystems, Milton-Keynes, UK). Mounted sections were washed in PBS and blocked/permeabilized with donkey serum $(10 \%$ in PBS, $0.2 \%$ Triton-X-100, $0.1 \%$ azide) for $1 \mathrm{~h}$ in a humidity chamber at room temperature. Primary antibodies against TLR4 (1:200, Abcam, Cambridge, UK), TLR7 (1:500, Novus Biologicals, Littleton, CO, USA), LPCAT1 (1:200, ProteinTech, Chicago, IL, USA) or LPCAT2 (1:200, Novus Biologicals, Littleton, CO, USA) were pooled with primary antibodies against either NF200 (1:4000, Sigma-Aldrich, Gillingham, UK), TRPV1 (1:200, Neuromics, Edina, MN, USA) or P2X3 (1:1000, Novus Biologicals, Littleton, CO, USA) and incubated with tissue sections for $24 \mathrm{~h}$, with the exception of TLR4 which required a 48-h incubation, in a humidity chamber at $4{ }^{\circ} \mathrm{C}$. After washing with PBS, tissue sections were incubated with a combination of species-specific alexafluor (AF) $488(10 \mu \mathrm{g} / \mathrm{mL}$, Life Technologies, Carlsbad,
CA, USA), AF555 $(10 \mu \mathrm{g} / \mathrm{mL}$, Life Technologies, Carlsbad, CA, USA) or AF594 $(10 \mu \mathrm{g} / \mathrm{mL}$, Jackson ImmunoResearch, West Grove, PA, USA) conjugated secondary antibodies for $3 \mathrm{~h}$ in a dark humidity chamber at room temperature. After washing with PBS, tissue sections were incubated with 4',6-diamidino-2-phe nylindole (DAPI) $\quad(100 \mathrm{ng} / \mathrm{mL}, \quad$ Sigma-Aldrich, Gillingham, UK) for $1 \mathrm{~h}$ in a humidity chamber at room temperature. Tissue sections were then mounted in FluorSave reagent (EMD Millipore, Watford, UK) for imaging.

A series of control experiments were performed to verify the specificity of the antibodies used in this study. The antibodies/antisera used for the neurochemical markers have been categorized elsewhere (Vulchanova et al., 1997; Guo et al., 1999; Michael and Priestley, 1999; Kiasalari et al., 2010). These antibodies/antisera performed as previously described when used in this study. Primary rat spleen tissue was used as a positive control for the TLR and LPCAT2 antibodies because of the high proportion of immune cells found in the spleen. Primary rat lung tissue was used as a positive control for LPCAT1. No blocking peptides were available for the primary antibodies used in this study. For the TLR antibodies we therefore performed staining on tissue known to be negative for the antigen in question. Peripheral rat red blood cells were used as negative controls for the TLR antibodies. Western blotting performed on whole TG samples was used to verify the specificity of the LPCAT antibodies and both displayed single bands at the expected weights. To test the specificity of the secondary antibodies TG sections were incubated with secondary antibodies in the absence of primary antibodies. Unstained TG sections were used to observe any autofluorescence within the tissue. No labeling was observed under the negative control conditions (control images not shown).

\section{Image acquisition \& analysis}

Images were captured using a Nikon Eclipse 80i epifluorescence microscope equipped with a Nikon DSQi1Mc camera using NIS-Elements software (BR 3.2, Nikon, New York, NY, USA). All images were taken using $20 \mathrm{X}$ or $60 \mathrm{X}$ objectives coupled with a $10 \mathrm{X}$ eyepiece. At least 2000 neuronal profiles from each tissue type and each animal were counted on randomly chosen tissue sections. Only neuronal profiles with a visible nuclear DAPI counterstain were included in the counting process. Image analysis and quantification were performed on monochrome images by a single investigator who was blinded to the slide identity. Subjective visual criteria were used to determine positive TLR4/TLR7/LPCAT1 immunoreactivity (IR). A threshold for positive counting was set using mean fluorescence intensity units, determined by two independent investigators for each antibody. Coexpression of TLR4, TLR7 and LPCAT with phenotypic markers was determined by positive identification of markers in individual images obtained by switching between TRITC and FITC filters. Following identification of positive profiles in individual images, co-expression 
was confirmed in merged images. Co-expression was expressed as a percentage of target markers expressing phenotypic markers and vice-versa.

\section{TG dissociation}

To investigate TLR-associated gene expression in TG sensory neurons, dissociated TG, rather than whole tissue samples were used in order to remove the majority of non-neuronal cells and non-cellular components. The protocol used for TG dissociation in this study was adapted from Malin et al. (2007). Briefly, male Sprague-Dawley rats were euthanized by exposure to rising concentrations of $\mathrm{CO}_{2}$. Animals were transcardially perfused with ice-cold HBSS (Calcium and Magnesium-free), TG were rapidly removed and cut into 10-12 small pieces. Tissue was incubated with papain solution (60 units papain, $1 \mathrm{mg}$ L-cysteine in HBSS) for $20 \mathrm{~min}$ at $37^{\circ} \mathrm{C}$ with gentle mixing halfway. Tissue was pelleted by centrifugation at $800 \mathrm{~g}$ for $3 \mathrm{~min}$ and the supernatant discarded. The tissue was resuspended in collagenase/dispase solution (12 mg collagenase type II and $14 \mathrm{mg}$ dispase type II in HBSS) and incubated for $20 \mathrm{~min}$ at $37^{\circ} \mathrm{C}$ with gentle mixing halfway. Pre-warmed trypsin inhibitor ( $1 \mathrm{mg} / \mathrm{mL}$ in HBSS) was added to stop enzymatic digestion and tissue was then pelleted by centrifugation at $800 \mathrm{~g}$ for $3 \mathrm{~min}$. Mechanical disruption by trituration with a sterile fire-polished, silicon-coated glass pipette in pre-warmed L15 medium created a single-cell suspension which was then passed through a $12.5 / 28 \%$ Percoll gradient at $1800 \mathrm{~g}$ for $10 \mathrm{~min}$ to yield a neuronenriched cell pellet which was immediately processed for RNA isolation.

\section{Real-time polymerase chain reaction ( $q P C R$ )}

Total messenger RNA (mRNA) from dissociated TG neurons and whole spleen tissue was isolated using RNAqueous-Micro kit according to the manufacturer's instructions. Isolated RNA was treated with DNase I for $20 \mathrm{~min}$ at $37^{\circ} \mathrm{C}$ to remove any genomic DNA contamination. Total RNA concentration was determined using a Qubit 2.0 Fluorometer with the Qubit RNA Assay Kit. Sample purity was assessed using a nanodrop 2000 (Thermo-Fisher Scientific, Waltham, MA, USA). Only samples with a 260/280 ratio of $>1.8$ were used for reverse transcription. First-strand cDNA was synthesized from $100 \mathrm{ng}$ RNA using the SuperScript VILO cDNA Synthesis Kit which contained SuperScript III reverse transcriptase (Reaction conditions: $25^{\circ} \mathrm{C}$ for $10 \mathrm{~min}, 42^{\circ} \mathrm{C}$ for $2 \mathrm{~h}, 85^{\circ} \mathrm{C}$ for $5 \mathrm{~min}$ ). cDNA was stored at $-20^{\circ} \mathrm{C}$ until used for $\mathrm{qPCR}$. Relative quantification was achieved with qPCR using TaqMan Gene Expression Assays for TLR4 (Rn00569848_m1), MD-1 (Rn01434815_m1), MD-2 (Rn01448830_m1), CD14 (Rn00572656_m1), MyD88 (Rn01640049_m1) and TRIF-related adapter molecule (TRAM) (Rn02082 474_s1) with glyceraldehyde 3-phosphate dehydrogen ase (GAPDH, Rn01775763_g1) as the endogenous control. All qPCR experiments used TaqMan Fast Advanced Master Mix and were performed in triplicate on a QuantStudio 12 k Flex system with a Fast 96-well
Block using $2.5 \mathrm{ng}$ of template cDNA in a total reaction volume of $10 \mu \mathrm{L}$ per well. The reaction parameters were as follows $-50^{\circ} \mathrm{C}$ for $2 \mathrm{~min}, 95^{\circ} \mathrm{C}$ for $20 \mathrm{~s}, 40$ cycles of $95^{\circ} \mathrm{C}$ for $1 \mathrm{~s}$ and $60^{\circ} \mathrm{C}$ for $20 \mathrm{~s}$. An initial no RT control for each sample type was performed to assess the effectiveness of the DNAse treatment used which returned an undetectable result. No template controls were also included in every run and returned undetectable results. A gene expression profile from each tissue type was created using $\Delta C^{T}$ values, with GAPDH set at 100. Analysis of gene expression data between tissue types was performed using the $2^{\Delta \Delta C T}$ method (Livak and Schmittgen, 2001) with target gene expression in each sample normalized against the endogenous control gene GAPDH.

\section{Statistical analysis}

Data are displayed as mean \pm SEM, $n=3$. Comparisons between groups were made using a Student's $t$-test, as appropriate, performed on IBM SPSS statistics software version 21.0 ( 1 animal $=1$ unit for statistical analysis). Differences were considered statistically significant when $p<0.05$.

\section{RESULTS}

\section{Expression of TLR4 \& TLR7 within the adult mammalian TG \& DRG}

Indirect single-labeling IHC was used to investigate the expression of TLR4 and TLR7 within the naïve adult rat TG and DRG. Multiple neuronal profiles displayed TLR4- and TLR7-IR in the TG and DRG (Fig. 1).
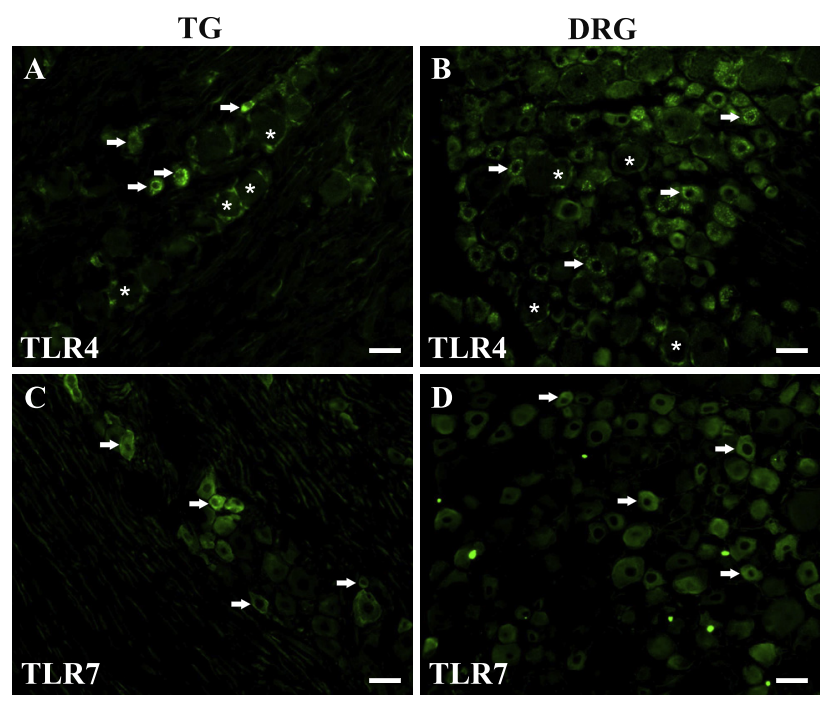

Fig. 1. TLR4 and TLR7 expression within the TG and DRG. Multiple neuronal profiles display intracellular granular IR for TLR4 within the TG (A) and DRG (B), arrows show selected examples of positive neurons. A proportion of non-neuronal cells that were morphologically identified as satellite cells also display a positive stain for TLR4 within both TG and DRG, indicated by asterisks (A, B). Multiple neuronal profiles also display positive IR for TLR7 within the TG (C) and DRG (D), arrows show selected examples. All non-neuronal cells within the tissue are negative for TLR7. Scale bar $50 \mu \mathrm{m}$. 
Whereas the expression of TLR7 was strictly neuronal, a proportion of non-neuronal cells that were morphologically identified as satellite cells (elongated fusiform cells that envelope neuronal soma) also expressed TLR4 (Fig. 1A, B). Non-neuronal staining was differentiated from neuronal membrane staining by carefully examining the co-expression patterns with neuronal markers and also by identifying the nonneuronal cell nucleus. No overlap of staining with neuronal markers was observed and clear, distinguishable nuclei were identified hence we characterized this staining as non-neuronal.

TLR4 was expressed by $29.3 \pm 3.4 \%$ and $32 \pm 2.9 \%$ of total sensory neurons in the TG and DRG, respectively. TLR7 was expressed by $32.4 \pm 1.8 \%$ and $35 \pm 3.9 \%$ of sensory neurons in the TG and DRG, respectively. There was no significant difference in expression levels of TLR4 and TLR7 between the TG and DRG (Student's $t$-test). TLR4-/TLR7-IR neurons are expressed as a percentage of total neuronal profiles as defined using a DAPI counterstain. Rat spleen tissue was used as a positive control and displayed multiple TLR4- and TLR7IR cells, respectively (Fig. 2). Red blood cells were used as a negative control tissue as they do not express TLR4 or TLR7. No staining was observed in the negative control tissue (Fig. 3). Spleen tissue was stained in the absence of primary antibodies to assess the specificity of the secondary antibodies used. No staining was observed under these conditions (Fig. 4).

\section{Co-expression of TLR4 \& TLR7 with neurochemical markers of functional sensory neuron populations}

Indirect dual-labeling IHC was used to characterize the degree of co-expression of TLR4 and TLR7 with neurochemical markers that are indicative of functional sensory neuron populations within the naïve adult rat TG and DRG. TLR4-IR was commonly observed in TRPV1- and P2X3-expressing neurons, respectively (Fig. 5A-F). However, in contrast to TRPV1 and P2X3, TLR4 was virtually absent from all NF200-expressing neurons (Fig. 5G-I).

Similar to TLR4, TLR7-IR was identified in a large proportion of TRPV1- and P2X3-expressing neurons, respectively (Fig. 6A-F). TLR7 and NF200 expression was also mutually exclusively (Fig. 6G-I). Similar patterns of co-expression were observed for TLR4 and TLR7 within the TG and DRG. A full characterization of TLR4 and TLR7 co-localization within the TG and DRG is shown in Table 1.

There was a significant difference between TLR4 and TLR7 in their relative levels of co-expression with the nociceptor markers used. TLR4 co-localized more frequently with $\mathrm{P} 2 \mathrm{X} 3$-positive neurons compared to TRPV1-positive neurons (TLR4/TRPV1 co-expression vs. TLR4/P2X3 co-expression, $p<0.0001$ for TG and DRG, Student's $t$-test). In the TG, TLR7 co-localized more frequently with TRPV1-positive neurons compared to P2X3-positive neurons (TLR7/TRPV1 co-expression vs. TLR7/P2X3 co-expression, $p<0.05$ for TG, Student's $t$-test.
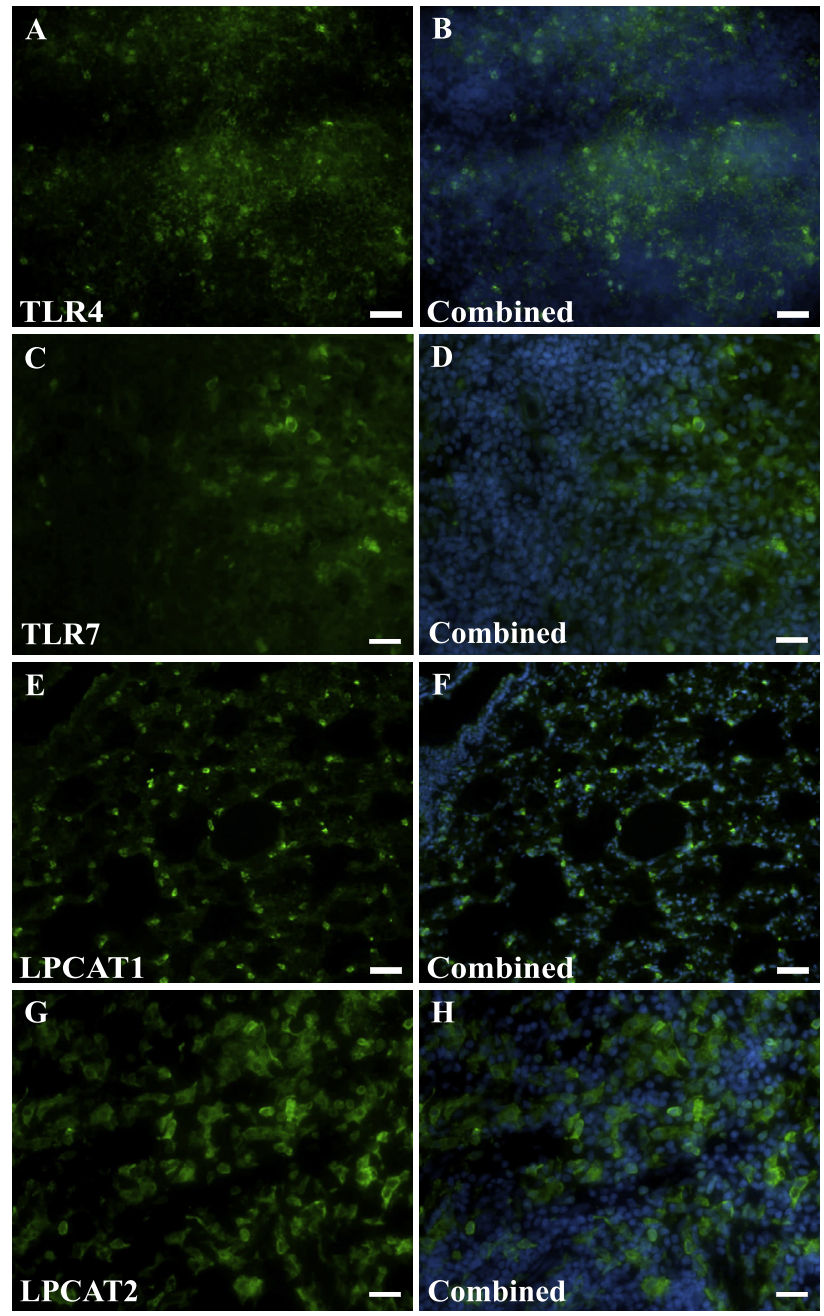

Fig. 2. Positive control staining of primary antibodies. Multiple positively stained profiles can be identified for TLR4 (A, B), TLR7 $(C, D)$ and LPCAT2 (E, F) in the spleen and LPCAT1 $(G, H)$ in the lung. Scale bar $15 \mu \mathrm{m}$ and $50 \mu \mathrm{m}$ for spleen and lung images, respectively.

\section{Expression of TLR4 signaling-associated molecules in TG sensory neurons}

We performed qPCR on dissociated TG sensory neurons in order to create a gene expression profile for TLR4 signaling-associated components. We evaluated the gene expression of TLR4 and three TLR4 co-receptor molecules, MD-1, MD-2 and CD14, as well as two intracellular signaling molecules that represent two pathways of the TLR4 intracellular signaling cascade, MyD88 and TRAM. The MyD88 pathway is also downstream from all other TLRs, with the exception of TLR3. For reference purposes, we have also included the pain-associated genes TRPV1, P2X3 and TrkA. The expression of these target genes relative to the housekeeping gene GAPDH (set at 100) is shown for TG sensory neurons (Fig. 7A) and control (spleen tissue, Fig. 7B), respectively. All target genes are expressed in TG sensory neurons $\left(C^{T}<35\right)$ albeit at lower levels than TRPV1, P2X3 and TRKA expression, respectively (Fig. 7A). Gene expression levels of the 

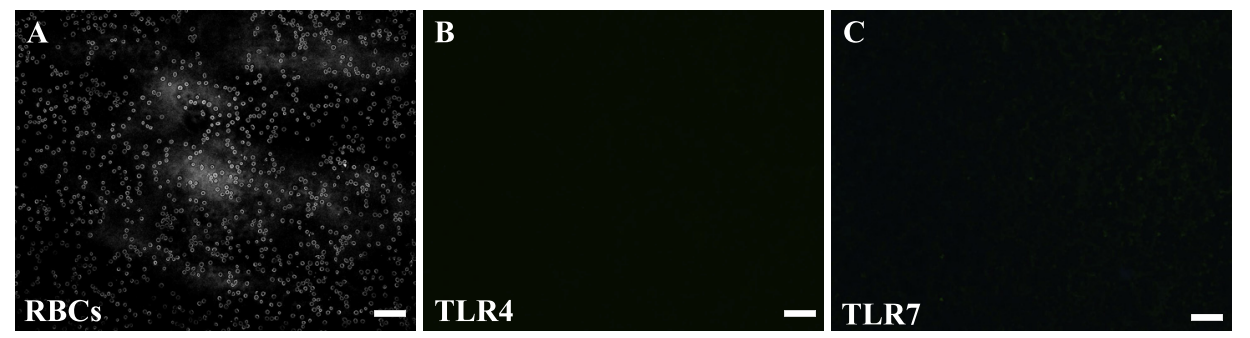

Fig. 3. TLR expression in red blood cells as a negative control. Phase-contrast microscopy was used to identify red blood cells (A). No positive staining was observed in red blood cells for TLR4 (B) or TLR7 (C) antibodies. Scale bar $50 \mu \mathrm{m}$.

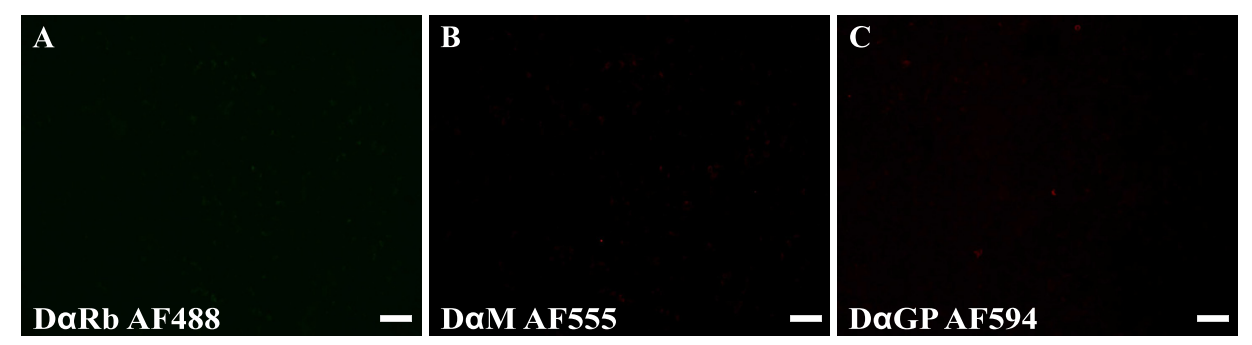

Fig. 4. Secondary antibody control staining in spleen tissue. Tissue staining was performed in the absence of primary antibody in order to observe non-specificity of secondary antibodies. Minimal levels of non-specific background staining were observed for Donkey anti-Rabbit AF488 (A), Donkey anti-Mouse AF555 (B) and Donkey ant-Guinea Pig AF594 (C). Scale bar $50 \mu \mathrm{m}$.

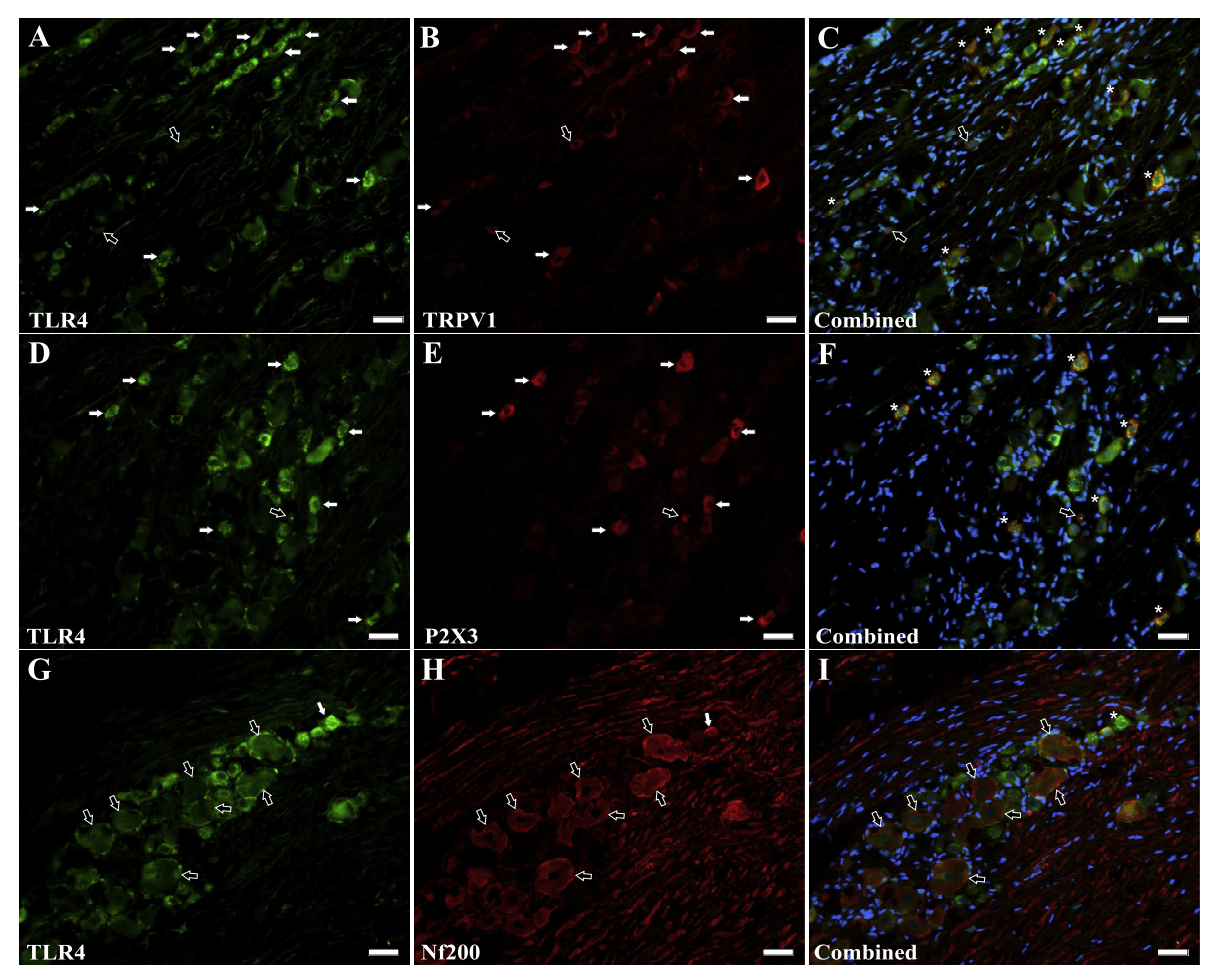

Fig. 5. Fluorescence micrograph of rat TG dual-labeled for TLR4-IR (green, A, D, G) plus either TRPV1- (red, B), P2X3- (red, E) or NF200-IR (red, $\mathrm{H})$. The combined images (C, F, I) show co-localization of TLR4-IR with neurochemical markers. A substantial proportion of TLR4-IR neurons coexpress TRPV1-IR, examples of co-expressing neurons are indicated by filled arrows (A, B) and by asterisks in the combined image (C). Not all TRPV1-IR neurons express TLR4, examples indicated by open arrows (A, B, C). A substantial proportion of TLR4-IR neurons also co-express P2X3-IR, examples of co-expressing neurons are indicated by filled arrows (D, E) and by asterisks in the combined image $(F)$. Also however, not all P2X3-IR neurons express TLR4, examples indicated by open arrows (D, E, F). There was minimal co-localization between TLR4-IR and NF200-IR; examples of co-expressing neurons are indicated by filled arrows $(\mathrm{G}, \mathrm{H})$ and by asterisks in the combined image (I). The majority of NF200-IR neurons did not express TLR4-IR, examples indicated by open arrows $(G, H, I)$. A similar pattern of expression and co-expression was observed in the DRG (images not shown). Scale bar $50 \mu \mathrm{m}$. (For interpretation of the references to colour in this figure legend, the reader is referred to the web version of this article.) 


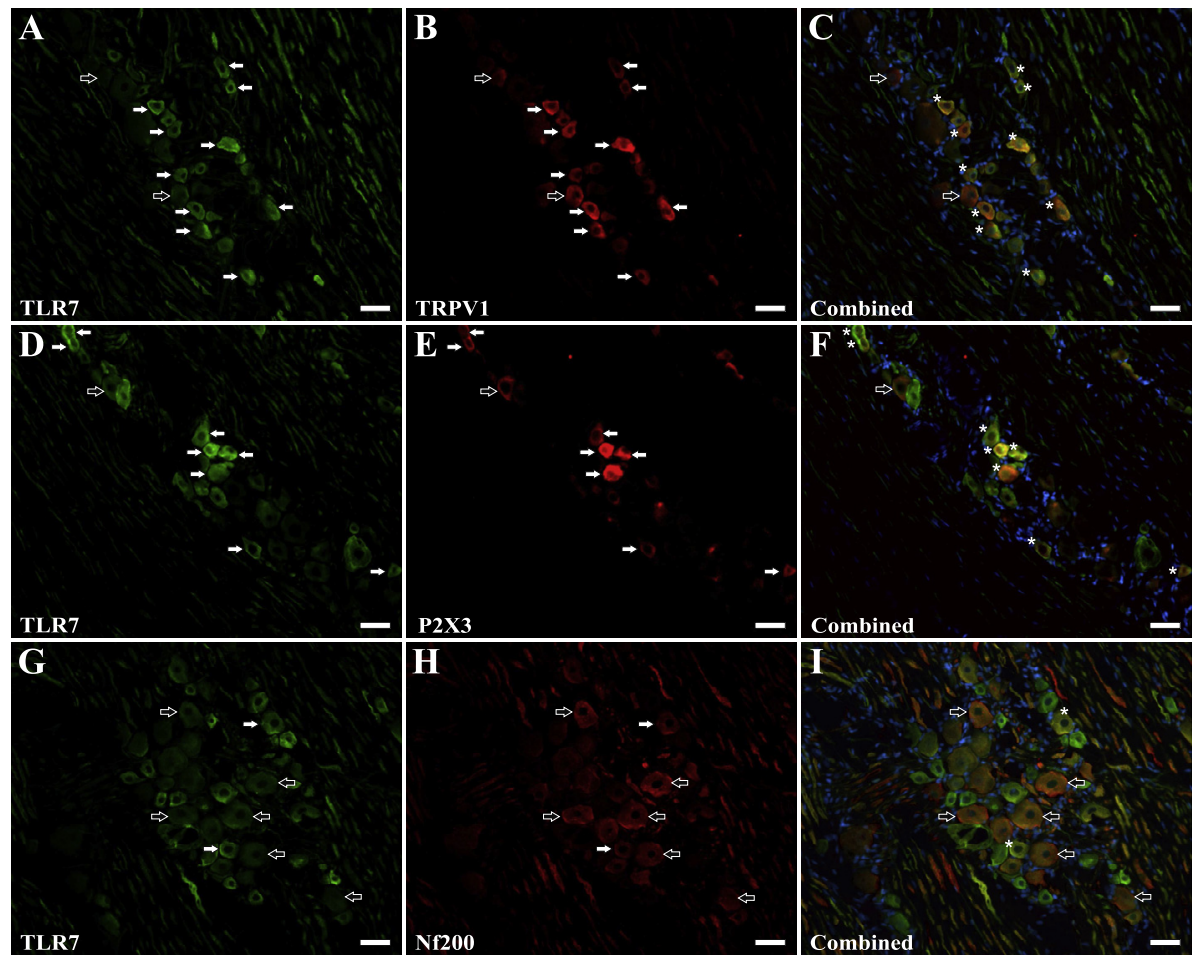

Fig. 6. Fluorescence micrograph of rat TG double labeled for TLR7-IR (green, A, D, G) plus either TRPV1- (red, B), P2X3- (red, E) or NF200-IR (red, H). The combined images (C, F, I) show co-localization of TLR7-IR with neurochemical markers. A substantial proportion of TLR7-IR neurons co-express TRPV1-IR, examples of co-expressing neurons are indicated by filled arrows (A, B) and by asterisks in the combined image (C). Some neurons expressing low levels of TRPV1-IR neurons do not display TLR7-IR, examples indicated by open arrows (A, B, C). A substantial proportion of TLR7-IR neurons also co-express P2X3-IR, examples of co-expressing neurons are indicated by filled arrows (D, E) and by asterisks in the combined image $(F)$. Also however, not all P2X3-IR neurons display TLR7-IR, examples indicated by open arrows (D, E, F). There was minimal colocalization between TLR7-IR and NF200-IR; examples of co-expressing neurons are indicated by filled arrows (G, H) and by asterisks in the combined image (I). The vast majority of NF200-IR neurons did not express TLR7-IR, examples indicated by open arrows (G, H, I). A similar pattern of expression and co-expression was observed in the DRG (images not shown). Scale bar $50 \mu \mathrm{m}$. (For interpretation of the references to colour in this figure legend, the reader is referred to the web version of this article.)

Table 1. Summary of TLR4 and TLR7 co-localization with the neurochemical markers TRPV1, P2X3 and NF200 within the naïve adult rat TG and DRG. Co-expression was expressed as a percentage of target markers expressing phenotypic markers and vice-versa

\begin{tabular}{lccll}
\hline $\begin{array}{l}\text { Neurochemical } \\
\text { label }\end{array}$ & $\begin{array}{l}\text { \% of labeled cells that } \\
\text { express TLR4 }\end{array}$ & $\begin{array}{l}\text { \% of TLR4-positive cells that } \\
\text { express label }\end{array}$ & $\begin{array}{l}\text { \% of labeled cells that } \\
\text { express TLR7 }\end{array}$ & $\begin{array}{l}\text { \% of TLR7-positive cells that } \\
\text { express label }\end{array}$ \\
\hline TG & & & & $42.6 \pm 8.1$ \\
TRPV1 & $53.7 \pm 0.9$ & $57.8 \pm 0.9$ & $75.7 \pm 2.5$ & $33.4 \pm 3.1$ \\
P2X3 & $76.6 \pm 0.4$ & $58.2 \pm 2$ & $61.6 \pm 2.1$ & - \\
NF200 & $3.5 \pm 0.7$ & $9.2 \pm 1.5$ & - & $45.5 \pm 10.5$ \\
DRG & & & $78.6 \pm 2.6$ & $32.5 \pm 4.8$ \\
TRPV1 & $56.1 \pm 1.4$ & $68.2 \pm 4.7$ & $54.8 \pm 9.4$ & - \\
P2X3 & $81.9 \pm 0.6$ & $76.5 \pm 2.5$ & - & \\
NF200 & $4 \pm 1.3$ & $6.9 \pm 2.1$ & & \\
\hline
\end{tabular}

TLR-associated components within TG sensory neurons were also compared to those of the primary spleen tissue which is known to contain a broad range of TLRexpressing immune cells. All genes are expressed at lower levels in TG sensory neurons than in the spleen tissue (Fig. 7C). MD-1 was expressed 290.1 \pm 36.3-fold lower in TG sensory neurons compared to primary spleen tissue although this is not surprising given the high B lymphocyte content of the spleen tissue (Cesta, 2006). TLR4 gene expression was the most comparable between the different tissue types with a $9.1 \pm 1.1$-fold lower expression in TG sensory neurons. The remaining targets were expressed $9.8 \pm 2.1$ (TRAM), $13 \pm 2.1$ (MD-2), $24.5 \pm 3.1$ (MyD88) and $40 \pm 8.2$ (CD14) fold lower in TG sensory neurons than the spleen.

\section{Expression of LPCAT isoforms in the TG}

We performed indirect single- and dual-labeling IHC to investigate the expression of LPCAT1 and LPCAT2 within the TG and DRG and their co-expression with neurochemical markers. LPCAT1-IR was identified in 

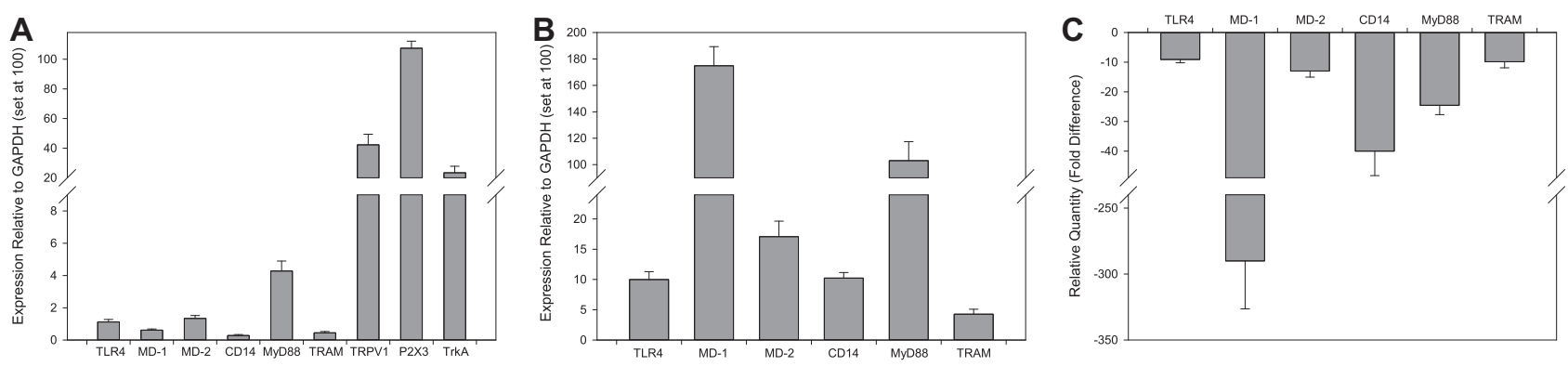

Fig. 7. TLR4 signaling-associated component gene expression in dissociated TG sensory neurons (A) and spleen tissue (B) as determined by qPCR. All genes are expressed relative to GAPDH levels (set at 100). Three pain-associated genes are also included in (A) for reference purposes. All targets are expressed in sensory neurons $\left(C^{T}<35\right)$. All TLR-associated genes are expressed at noticeably lower levels than each of the three pain-associated genes, respectively. The difference in gene expression between TG sensory neurons and spleen tissue is calculated using the $\Delta \Delta C^{T}$ method (C). All targets are expressed in TG sensory neurons at lower levels compared to spleen tissue. Data are displayed as mean $\pm \mathrm{S}$.E. M., $n=3$.

$50.4 \pm 4.5 \%$ of total neurons (Fig. 8A, B). A proportion of non-neuronal cells that were morphologically identified as satellite cells also displayed weak IR for LPCAT1 (Fig. 8A, B).

LPCAT1 was expressed by $86.3 \pm 4.7 \%, 67 \pm 7.9 \%$ and $47.7 \pm 5.3 \%$ of TRPV1-, P2X3- and NF200expressing neurons, respectively (Fig. 9).

All neuronal profiles were negative for LPCAT2 but the majority of non-neuronal cells displayed strong LPCAT2IR (Fig. 8C, D).

Rat lung and spleen tissue were used as positive control tissues for LPCAT1 and LPCAT2, respectively. Multiple positively stained cells can be identified (Fig. 2E-H). As LPCAT isoforms are expressed across a range of tissue types we used western blotting to demonstrate the specificity of the primary antibodies. A single band at the expected molecular weight was identified for both LPCAT1 and LPCAT2 in the TG, DRG, cortex and RAW264.7 cells (Fig. 10).

\section{DISCUSSION}

Previous studies have shown both TLR4 and TLR7 to be expressed by nociceptors within mammalian sensory ganglia (Wadachi and Hargreaves, 2006; Liu et al., 2010; Qi et al., 2011; Due et al., 2012; Park et al., 2014) however this is the first quantitative description of TLR4 and TLR7 expression within adult mammalian
TG
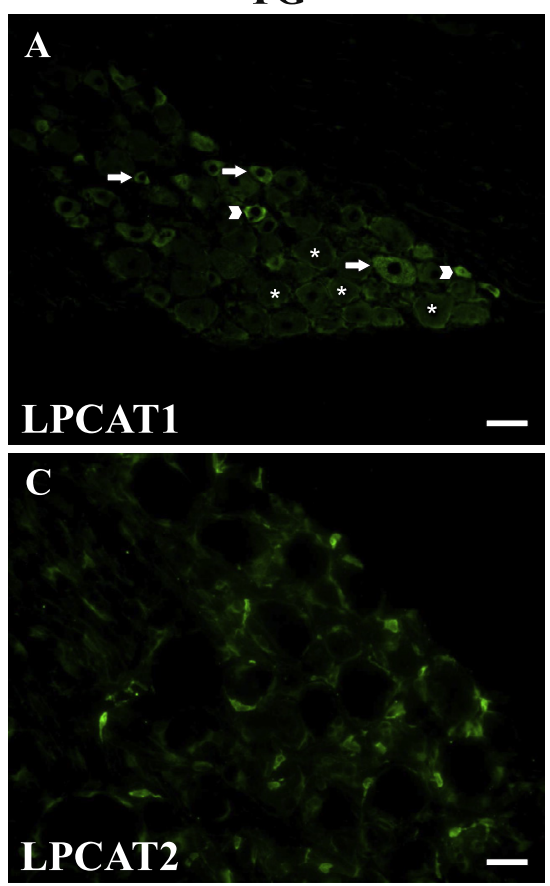

DRG
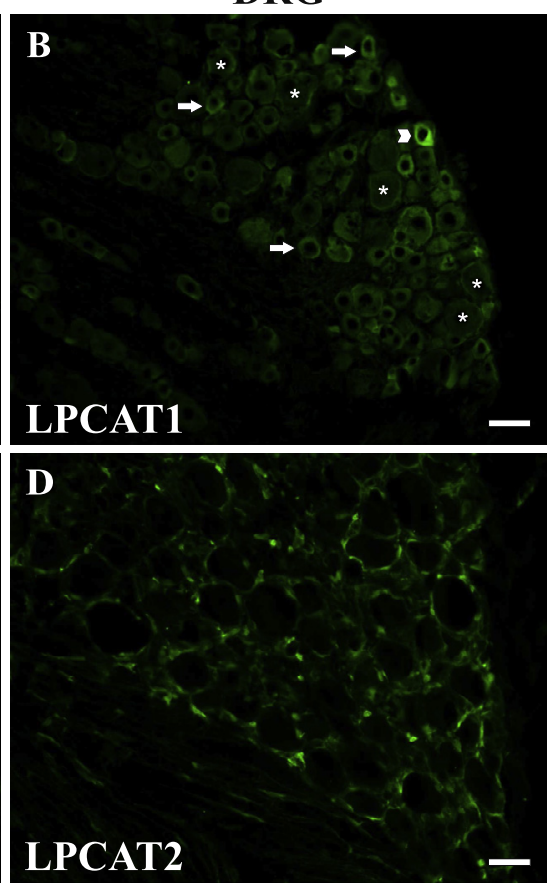

Fig. 8. LPCAT1 and LPCAT2 expression within the TG and DRG. Approximately half of the total neuronal profiles within the TG displayed LPCAT1$I R$, arrows show selected examples (A). A similar pattern of expression was seen in the DRG (B). A proportion of non-neuronal cells that were morphologically identified as satellite cells also displayed weak LPCAT1-IR, examples indicated by asterisks (A, B). LPCAT2-IR was not detected above threshold levels within any neuronal profile in either TG or DRG. However the majority of non-neuronal cells identified morphologically as satellite cells, displayed strong LPCAT2-IR within both TG (C) and DRG (D). Scale bar $50 \mu \mathrm{m}$. 


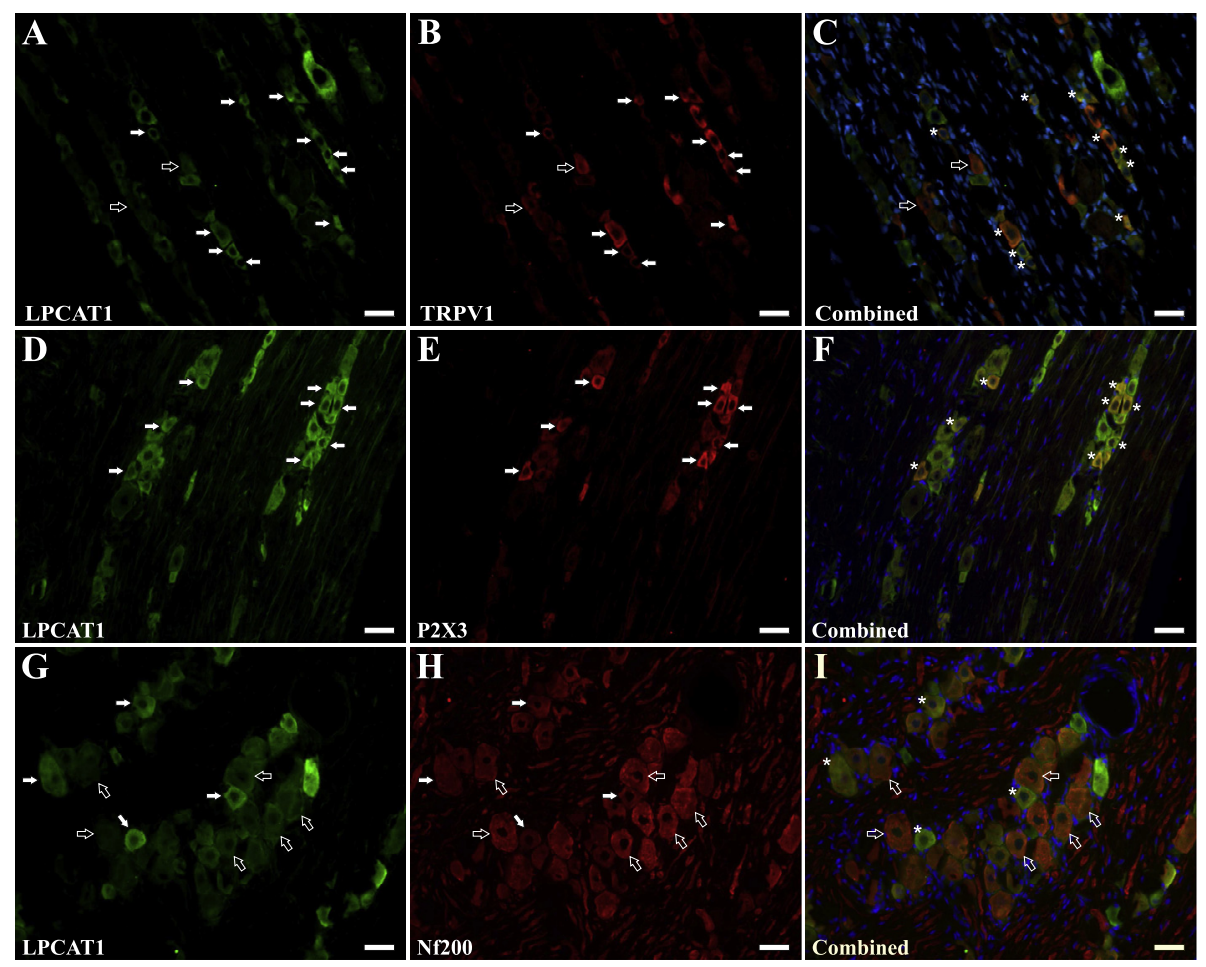

Fig. 9. Fluorescence micrograph of rat TG double labeled for LPCAT1-IR (green, A, D, G) plus either TRPV1-(red, B), P2X3-(red, E) or NF200-IR (red, H). The combined images (C, F, I) show co-localization of LPCAT1-IR with neurochemical markers. LPCAT1-IR shows co-expression with a substantial proportion of TRPV1-IR neurons, examples of co-expressing neurons are indicated by filled arrows (A, B) and by asterisks in the combined image (C). Not all neurons displaying TRPV1-IR neurons express LPCAT1-IR, examples indicated by open arrows (A, B, C). The majority of LPCAT1-IR neurons also co-express P2X3-IR; examples of co-expressing neurons are indicated by filled arrows (D, E) and by asterisks in the combined image $(F)$. A proportion of LPCAT1-IR neurons also co-express NF200-IR, examples of co-expressing neurons are indicated by filled arrows $(\mathrm{G}, \mathrm{H})$ and by asterisks in the combined image (I). There were also a population of NF200-IR neurons that did not co-express LPCAT1-IR, examples indicated by open arrows (G, H, I). A similar pattern of expression and co-expression was observed in the DRG (images not shown). Scale bar $50 \mu \mathrm{m}$. (For interpretation of the references to colour in this figure legend, the reader is referred to the web version of this article.)

A

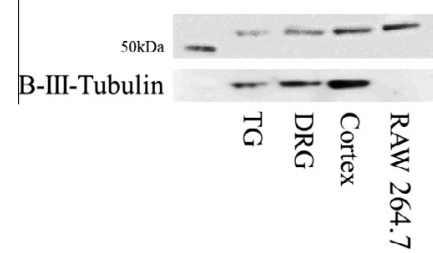

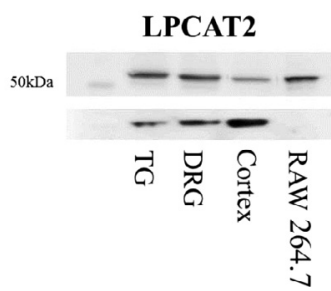

Fig. 10. Western Blot control for LPCAT isoform expression across multiple tissue types. LPCAT1 (A; 1:1000) and LPCAT2 (B; 1:500) expression in TG, DRG and cortex. $20 \mu \mathrm{g}$ of protein was run in each lane. RAW 264.7 cells were used as a positive control. $\beta$-III tubulin was used as a loading control. Images representative of three separate experiments $(n=3)$.

sensory ganglia in relation to functional neuronal phenotype. Here we show that TLR4 and TLR7 are expressed by both capsaicin- and ATP-responsive nociceptors due to a high degree of co-expression with TRPV1 and P2X3, respectively. We show that dissociated sensory neurons from the TG express a range of TLR4-associated genes that are required for a full TLR4 signaling response. We also show that LPCAT1 and LPCAT2 are expressed within sensory ganglia although only LPCAT1 displays neuronal expression in naïve tissue.

Our TLR4 expression data fall within the range of expression observed in previous studies on DRG tissue sections (28-34\% of total neurons; Due et al., 2012; Tse et al., 2014b). Previous studies have reported that non-neuronal cells do not express TLR4 (Due et al., 2012; Tse et al., 2014a) however here we show that a proportion of satellite cells do indeed display TLR4-IR. There was no difference in expression levels of TLR4 and TLR7 between the TG and DRG. Interestingly however there was a significant difference between TLR4 and TLR7 in their relative levels of co-expression with the nociceptor markers used. TLR4 co-localized more frequently with P2X3-positive neurons whilst TLR7 colocalized more frequently with TRPV1-positive neurons. 
The functional significance of this observation is currently unknown although Park et al. (2014) have recently shown that TLR7 interacts with TRPA1, expressed by a proportion of TRPV1-positive neurons, to directly activate sensory neurons. We found minimal co-localization between TLR4/TLR7 and NF200 suggesting that TLR4 and TLR7 selectively localize to C-fiber nociceptors. Preferential and direct activation and/or sensitization of $\mathrm{C}$-fiber nociceptors by pathogens and damage-released endogenous molecules (DAMPs) via TLR4 and TLR7 is therefore potentially possible.

There is now extensive evidence for the involvement of neuroimmune signaling in the development and maintenance of chronic pain states (reviewed by Nicotra et al., 2012). TLRs are an important receptor family involved in the complex intercellular signaling network that develops in the setting of chronic inflammatory pain. TLR4 is the most widely studied member of the receptor family in this regard and it is rapidly up-regulated following the onset of both inflammatory and neuropathic pain (DeLeo et al., 2004; Raghavendra et al., 2004; Zhao and Zhang, 2015). TLR4 deletion (Tanga et al., 2005) and pharmacological inhibition have both been shown to prevent (Bettoni et al., 2008) and reverse behavioral hypersensitivity (Hutchinson et al., 2007, 2008, 2010; Lan et al., 2010; Wu et al., 2010) and decrease the production of pro-inflammatory mediators in models of neuropathic pain (Tanga et al., 2005; Lan et al., 2010). Importantly, the involvement of TLR4 in the development and maintenance of chronic pain has also been demonstrated in a human model. A low intravenous dose of LPS sensitized nociceptors to a subsequent capsaicin challenge and participants experienced an increase in capsaicin-dependent flare, allodynia and hyperalgesia however the effect of LPS on neurons in this study is likely to be mainly indirect (Hutchinson et al., 2013). These findings have been extended to include the contribution of TLR2 and TLR3 to central nervous system preclinical pain models (Kim et al., 2007; Obata et al., 2008; Mei et al., 2011). TLR3 (Liu et al., 2012) and TLR7 (Park et al., 2014) activation has also been shown to directly activate peripheral sensory neurons in the murine DRG. Early research in this field has focussed mainly on TLR4 however more TLRs are emerging as important mediators of pain hypersensitivity. Whilst the role, for example, of TLR7 in clinical pain models has yet to be studied, peripheral blood mononuclear cells from chronic pain patients display increased responsiveness to TLR7 ligand stimulation, as well as TLR2 and TLR4 (Kwok et al., 2012).

Based on the findings of the current study, plus others, it is likely that TLR activation may occur directly and preferentially on nociceptors without the necessary intervention of the innate immune system. The ability of neurons to directly detect and respond to pathogenic ligands represents a rapid response mechanism that has significant consequences for acute nociceptor activation, sensitization and altered neuronal/nonneuronal cell communication. There is also potential for sensory neurons to detect DAMPs (Goh and Midwood, 2011) and this has been demonstrated in TG (Ohara et al., 2013) and DRG (Miller et al., 2014; Park et al.,
2014) sensory neurons. Following TLR4 activation, for example, peripheral sensory neurons display increased excitability (Ochoa-Cortes et al., 2010; Due et al., 2012), sensitization of TRPV1 and potentiation of TRPV1dependent neuropeptide production (Diogenes et al., 2011; Ferraz et al., 2011). Various pro-inflammatory mediators are also induced downstream from TLR4 activation (Ochoa-Cortes et al., 2010; Tse et al., 2014a). Neuronal TLR7 activation induces rapid inward currents and action potentials to increase neuronal excitability through mechanisms involving TRPA1 (Liu et al., 2010, 2012; Park et al., 2014). An up-regulation and sensitization of TRPV1 and induction of pro-inflammatory mediators is also observed following neuronal TLR7 activation (Qi et al., 2011). It is likely that these mediators can further act through autocrine and/or paracrine mechanisms to further alter nociceptive responses and contribute to the local inflammatory response (Opree and Kress, 2000; Sommer and Kress, 2004; Binshtok et al., 2008; Milligan and Watkins, 2009; Uceyler et al., 2009; Zhang et al., 2011; Ji et al., 2013).

This study is the first to demonstrate a co-localization between TLR4 and TLR7 with P2X3-expressing neurons. P2X3 activation, by ATP, induces rapid nociceptor depolarization which plays a prominent role in the sensitization of nociceptors and alteration of neuronal/ non-neuronal cell communication following the onset of neuroinflammation (Fabbretti, 2013). It is known that LPS evokes an up-regulation and sensitization of P2X3 receptors in primary TG neuron cultures although it is not known whether this is through a direct action on neurons or secondary to the activation of non-neuronal cells and subsequent release of ATP and inflammatory mediators (Franceschini et al., 2013). Here we show that a large proportion of P2X3-positive neurons co-express TLR4 and TLR7 suggesting that bacterial and viral infection, respectively, could directly modulate $\mathrm{P} 2 \mathrm{X} 3$ receptor function. We suggest that the activation of TLR4 and TLR7 could be sufficient to sensitize P2X3 in a similar manner to that of TLR4-dependent TRPV1 sensitization.

The exact composition of the TLR4 co-receptor complex that is required for neuronal TLR4 activation remains unclear. The co-localization of TLR4 with the co-receptor CD14 has been identified in capsaicinresponsive nociceptors within the TG (Wadachi and Hargreaves, 2006) and the involvement of CD14 in neuropathic pain has been demonstrated (Cao et al., 2009). However there is conflicting evidence as to whether MD1 or MD-2 is involved in neuronal TLR4 signaling. In innate immune cells the TLR4 receptor complex consists of TLR4, CD14 and MD-2 (Akashi-Takamura and Miyake, 2008). MD-1, a MD-2 homolog, normally forms a complex with RP105, a TLR4 homolog that lacks an intracellular Toll/Interleukin-1 receptor (TIR) homology domain (Medzhitov, 2001). One study has shown that neuronal TLR4 interacts with MD-1 rather than the conventional co-receptor MD-2 (Acosta and Davies, 2008). This latter study also showed lack of MD-2 expression in DRG sensory neurons. However more recent studies have identified both MD-1 and MD-2 mRNA and protein expression in DRG nociceptors and shown a preferential co- 
localization of TLR4 with MD-2 (Ochoa-Cortes et al., 2010; Tse et al., 2014a). The present study shows that acutely dissociated TG sensory neuron preparations express TLR4, CD14, MD-1, MD-2, MyD88 and TRAM mRNA. This in agreement with Tse et al. (2014a) and Ochoa-Cortes et al. (2010) that sensory neurons express both MD-1 and MD-2. MyD88 and TRAM are also expressed by sensory neurons suggesting that both the MyD88-dependent and MyD88-independent branches of the TLR4-signaling pathway are available following neuronal TLR4 activation. MyD88-dependent signaling downstream of neuronal TLR4 and Interleukin-1 $\beta$ (IL-1 $\beta$ ) receptor activation has been shown (Davis et al., 2006; Qi et al., 2011; Tse et al., 2014a) however the role of MyD88-independent signaling in peripheral sensory neurons is yet to be demonstrated. Given that the acutely dissociated sensory ganglia cell preparations used in this study contain a proportion of non-neuronal cells and we have shown that a small number of satellite cells display TLR4-IR it is therefore not possible to directly assign this expression purely to neurons. However, given the TLR expression patterns observed in this study as well as the techniques used when dissociating ganglia we believe that it is reasonable to suggest that the gene expression is largely neuronal. It is worth noting that co-receptor components, such as MD-2 and CD14, exist in soluble forms that are secreted from cells to actively participate in the LPS response (Bazil et al., 1989; Visintin et al., 2001). Therefore co-receptor components do not necessarily need to be expressed by neurons to mediate neuronal TLR4 signaling, a phenomenon which has been demonstrated in lung epithelial cells (Kennedy et al., 2004).

In monocytes, the group of phospholipid modifying enzymes known as lysophosphatidylcholine acyltransferases (LPCAT) is essential for the TLR4 response (Schmid et al., 2003; Jackson et al., 2008). TLR4 associates with lipid raft membrane domains, in an LPCAT-dependent manner, in order to activate intracellular signaling cascades (Triantafilou et al., 2002; Jackson et al., 2008). We have investigated whether specific isoforms of this enzyme, LPCAT1 and LPCAT2, are present in mammalian sensory ganglia and may therefore be involved in neuronal TLR signaling. Although multiple studies show that neuronal TLRs are functional, it is yet to be demonstrated that neuronal TLRs associate with lipid raft microdomains, as is seen in innate immune cells, to initiate these responses. Both isoforms are expressed within sensory ganglia however each displays a distinct expression pattern within the tissue. Approximately half of all TG sensory neurons counted in this study expressed LPCAT1. The expression of LPCAT1 was not exclusive to any one particular sub-population of sensory neuron; LPCAT1 co-localized to a proportion of TRPV1-, P2X3- and NF200-positive neurons within the TG. This suggests that LPCAT1 does not specifically mediate TLR4 signaling in sensory neurons and we suggest that LPCAT1 may play a role in more general membrane physiology common to all sensory neuron populations. Interestingly, we demonstrate a complete absence of LPCAT2 expression in sensory neurons within the naïve TG, suggesting little/no LPCAT2 activity in neu- rons under normal conditions. Therefore, based on the results presented in this study, we cannot suggest a role for LPCATs in neuronal TLR signaling. It has however been shown that, unlike LPCAT1, LPCAT2 is an inducible enzyme and both the expression and PAF synthesizing activity of LPCAT2 is up-regulated following LPS priming in monocytes (Shindou et al., 2005). Indeed, the expression of LPCAT2 has been identified in sensory neurons and non-neuronal cells in the DRG and spinal cord following nerve injury (Hasegawa et al., 2010; Okubo et al., 2012). Therefore nerve injury appears sufficient to provide a priming signal that increases LPCAT2 expression within peripheral and spinal sensory neurons. It is not known whether LPS exposure is sufficient to induce LPCAT2 expression in neurons and understanding this may be key to uncovering an association of LPCAT2 with neuronal TLR4 signaling.

\section{CONCLUSIONS}

The full extent of direct pathogen-neuron interactions is unknown and recently a mechanism for direct activation of nociceptors by bacterial $\mathrm{N}$-formylated peptides and the pore-forming toxin $\alpha$-hemolysin was identified (Chiu et al., 2013). Pain experienced in a murine model of Staphylococcus aureus skin infection correlated with bacterial load rather than immune involvement (Chiu et al., 2013). Therefore, direct pathogen-neuron interactions may play a more prominent role in the onset of pain hypersensitivity and may not be as reliant on immune cell involvement as was previously thought. A growing body of evidence suggests that TLRs expressed by nociceptors are able to directly influence nociceptor function and contribute to a neuroimmune signaling network involving neurons, non-neuronal and immune cells that act both centrally and peripherally to maintain chronic pain hypersensitivity. In this study we have described in detail the expression of TLR4, TLR7 and other TLR-associated molecules within the adult mammalian TG and DRG. Our results support a mechanism whereby nociceptors can directly detect and respond to pathogenic challenge independent of innate immune activation.

\section{REFERENCES}

Acosta C, Davies A (2008) Bacterial lipopolysaccharide regulates nociceptin expression in sensory neurons. J Neurosci Res 86:1077-1086

Akashi-Takamura S, Miyake K (2008) TLR accessory molecules. Curr Opin Immunol 20:420-425.

Akira S, Takeda K (2004) Toll-like receptor signalling. Nat Rev Immunol 4:499-511.

Austin PJ, Moalem-Taylor G (2010) The neuro-immune balance in neuropathic pain: involvement of inflammatory immune cells, immune-like glial cells and cytokines. J Neuroimmunol 229:26-50.

Barajon I, Serrao G, Arnaboldi F, Opizzi E, Ripamonti G, Balsari A, Rumio C (2009) Toll-like receptors 3, 4, and 7 are expressed in the enteric nervous system and dorsal root ganglia. J Histochem Cytochem 57:1013-1023.

Bazil V, Baudys M, Hilgert I, Stefanova I, Low MG, Zbrozek J, Horejsi V (1989) Structural relationship between the soluble and membrane-bound forms of human monocyte surface glycoprotein CD 14. Mol Immunol 26:657-662. 
Bettoni I, Comelli F, Rossini C, Granucci F, Giagnoni G, Peri F, Costa B (2008) Glial TLR4 receptor as new target to treat neuropathic pain: efficacy of a new receptor antagonist in a model of peripheral nerve injury in mice. Glia 56:1312-1319.

Binshtok AM, Wang H, Zimmermann K, Amaya F, Vardeh D, Shi L, Brenner GJ, Ji RR, Bean BP, Woolf CJ, Samad TA (2008) Nociceptors are interleukin-1beta sensors. J Neurosci 28:14062-14073.

Cameron JS, Alexopoulou L, Sloane JA, Dibernardo AB, Ma Y, Kosaras B, Flavell R, Strittmatter SM, Volpe J, Sidman R, Vartanian T (2007) Toll-like receptor 3 is a potent negative regulator of axonal growth in mammals. J Neurosci 27:13033-13041.

Cao L, Tanga FY, DeLeo JA (2009) The contributing role of CD14 in toll-like receptor 4 dependent neuropathic pain. Neuroscience 158:896-903.

Cesta MF (2006) Normal structure, function, and histology of the spleen. Toxicol Pathol 34:455-465.

Chiu IM, Heesters BA, Ghasemlou N, Von Hehn CA, Zhao F, Tran J, Wainger B, Strominger A, Muralidharan S, Horswill AR, Bubeck Wardenburg J, Hwang SW, Carroll MC, Woolf CJ (2013) Bacteria activate sensory neurons that modulate pain and inflammation. Nature 501:52-57.

Davis CN, Mann E, Behrens MM, Gaidarova S, Rebek M, Rebek J, Bartfai T (2006) MyD88-dependent and -independent signaling by IL-1 in neurons probed by bi-functional Toll/IL-1 receptor domain/ BB-loop mimetics. Proc Natl Acad Sci U S A 103:2953-2958.

DeLeo JA, Tanga FY, Tawfik VL (2004) Neuroimmune activation and neuroinflammation in chronic pain and opioid tolerance/ hyperalgesia. Neuroscientist 10:40-52.

Diogenes A, Ferraz CC, Akopian AN, Henry MA, Hargreaves KM (2011) LPS sensitizes TRPV1 via activation of TLR4 in trigeminal sensory neurons. J Dent Res 90:759-764.

Due MR, Piekarz AD, Wilson N, Feldman P, Ripsch MS, Chavez S, Yin H, Khanna R, White FA (2012) Neuroexcitatory effects of morphine-3-glucuronide are dependent on Toll-like receptor 4 signaling. J Neuroinflammation 9:200.

Fabbretti E (2013) ATP P2X3 receptors and neuronal sensitization. Front Cell Neurosci 7:236.

Ferraz CC, Henry MA, Hargreaves KM, Diogenes A (2011) Lipopolysaccharide from Porphyromonas gingivalis sensitizes capsaicin-sensitive nociceptors. J Endod 37:45-48.

Franceschini A, Hullugundi SK, Van Den Maagdenberg AM, Nistri A, Fabbretti E (2013) Effects of LPS on P2X3 receptors of trigeminal sensory neurons and macrophages from mice expressing the R192Q Cacna1a gene mutation of familial hemiplegic migraine-1. Purinergic Signal 9:7-13.

Goh FG, Midwood KS (2011) Intrinsic danger: activation of Toll-like receptors in rheumatoid arthritis. Rheumatology.

Grace PM, Rolan PE, Hutchinson MR (2011) Peripheral immune contributions to the maintenance of central glial activation underlying neuropathic pain. Brain Behav Immun 25:1322-1332.

Guo A, Vulchanova L, Wang J, Li X, Elde R (1999) Immunocytochemical localization of the vanilloid receptor 1 (VR1): relationship to neuropeptides, the P2X3 purinoceptor and IB4 binding sites. Eur J Neurosci 11:946-958.

Hasegawa S, Kohro Y, Shiratori M, Ishii S, Shimizu T, Tsuda M, Inoue K (2010) Role of PAF receptor in proinflammatory cytokine expression in the dorsal root ganglion and tactile allodynia in a rodent model of neuropathic pain. PLoS One 5:e10467.

Hutchinson MR, Bland ST, Johnson KW, Rice KC, Maier SF, Watkins LR (2007) Opioid-induced glial activation: mechanisms of activation and implications for opioid analgesia, dependence, and reward. Sci World J 7:98-111.

Hutchinson MR, Zhang Y, Brown K, Coats BD, Shridhar M, Sholar PW, Patel SJ, Crysdale NY, Harrison JA, Maier SF, Rice KC, Watkins LR (2008) Non-stereoselective reversal of neuropathic pain by naloxone and naltrexone: involvement of toll-like receptor 4 (TLR4). Eur J Neurosci 28:20-29.

Hutchinson MR, Loram LC, Zhang Y, Shridhar M, Rezvani N, Berkelhammer D, Phipps S, Foster PS, Landgraf K, Falke JJ,
Rice KC, Maier SF, Yin H, Watkins LR (2010) Evidence that tricyclic small molecules may possess toll-like receptor and myeloid differentiation protein 2 activity. Neuroscience 168:551-563.

Hutchinson MR, Buijs M, Tuke J, Kwok YH, Gentgall M, Williams D, Rolan P (2013) Low-dose endotoxin potentiates capsaicininduced pain in man: evidence for a pain neuroimmune connection. Brain Behav Immun 30:3-11.

Jackson SK, Abate W, Parton J, Jones S, Harwood JL (2008) Lysophospholipid metabolism facilitates Toll-like receptor 4 membrane translocation to regulate the inflammatory response. J Leukoc Biol 84:86-92.

Ji RR, Berta T, Nedergaard M (2013) Glia and pain: is chronic pain a gliopathy? Pain 154:S10-S28.

Kennedy MN, Mullen GED, Leifer CA, Lee C, Mazzoni A, Dileepan KN, Segal DM (2004) A complex of soluble MD-2 and lipopolysaccharide serves as an activating ligand for Toll-like receptor 4. J Biol Chem 279:34698-34704.

Kiasalari Z, Salehi I, Zhong Y, McMahon SB, Michael-Titus AT, Michael GJ (2010) Identification of perineal sensory neurons activated by innocuous heat. J Comp Neurol 518:137-162.

Kim D, Kim MA, Cho IH, Kim MS, Lee S, Jo EK, Choi SY, Park K, Kim JS, Akira S, Na HS, Oh SB, Lee SJ (2007) A critical role of toll-like receptor 2 in nerve injury-induced spinal cord glial cell activation and pain hypersensitivity. J Biol Chem 282:14975-14983.

Kwok YH, Hutchinson MR, Gentgall MG, Rolan PE (2012) Increased responsiveness of peripheral blood mononuclear cells to in vitro TLR 2, 4 and 7 ligand stimulation in chronic pain patients. PLoS One $7: \mathrm{e} 44232$.

Lafon M, Megret F, Lafage M, Prehaud C (2006) The innate immune facet of brain: human neurons express TLR-3 and sense viral dsRNA. J Mol Neurosci 29:185-194.

Lan LS, Ping YJ, Na WL, Miao J, Cheng QQ, Ni MZ, Lei L, Fang LC, Guang RC, Jin Z, Wei L (2010) Down-regulation of Toll-like receptor 4 gene expression by short interfering RNA attenuates bone cancer pain in a rat model. Mol Pain 6:2.

Liu T, Xu ZZ, Park CK, Berta T, Ji RR (2010) Toll-like receptor 7 mediates pruritus. Nat Neurosci 13:1460-1462.

Liu T, Berta T, Xu ZZ, Park CK, Zhang L, Lu N, Liu Q, Liu Y, Gao YJ, Liu YC, Ma Q, Dong X, Ji RR (2012) TLR3 deficiency impairs spinal cord synaptic transmission, central sensitization, and pruritus in mice. J Clin Invest 122:2195-2207.

Livak KJ, Schmittgen TD (2001) Analysis of relative gene expression data using real-time quantitative PCR and the 2(-Delta Delta C (T)) method. Methods 25:402-408.

Malin SA, Davis BM, Molliver DC (2007) Production of dissociated sensory neuron cultures and considerations for their use in studying neuronal function and plasticity. Nat Protoc 2:152-160.

Marchand F, Perretti M, McMahon SB (2005) Role of the immune system in chronic pain. Nat Rev Neurosci 6:521-532.

Medzhitov R (2001) Toll-like receptors and innate immunity. Nat Rev Immunol 1:135-145.

Mei XP, Zhou Y, Wang W, Tang J, Wang W, Zhang H, Xu LX, Li YQ (2011) Ketamine depresses Toll-like receptor 3 signaling in spinal microglia in a rat model of neuropathic pain. Neurosignals 19:44-53.

Michael GJ, Priestley JV (1999) Differential expression of the mRNA for the vanilloid receptor subtype 1 in cells of the adult rat dorsal root and nodose ganglia and its downregulation by axotomy. J Neurosci 19:1844-1854.

Miller RE, Tran PB, Ishihara S, Miller RJ, Malfait AM (2014) Damps provide a link between joint tissue damage and pain through direct activation of TLR4 expressed by sensory neurons. Osteoarthr Cartilage 22:S416-S417.

Milligan ED, Watkins LR (2009) Pathological and protective roles of glia in chronic pain. Nat Rev Neurosci 10:23-36.

Mishra BB, Mishra PK, Teale JM (2006) Expression and distribution of Toll-like receptors in the brain during murine neurocysticercosis. J Neuroimmunol 181:46-56.

Morimoto R, Shindou H, Oda Y, Shimizu T (2010) Phosphorylation of lysophosphatidylcholine acyltransferase 2 at Ser34 enhances 
platelet-activating factor production in endotoxin-stimulated macrophages. J Biol Chem 285:29857-29862.

Nakanishi H, Shindou H, Hishikawa D, Harayama T, Ogasawara R, Suwabe A, Taguchi R, Shimizu T (2006) Cloning and characterization of mouse lung-type acyl-CoA: lysophosphatidylcholine acyltransferase 1 (LPCAT1). Expression in alveolar type II cells and possible involvement in surfactant production. J Biol Chem 281:20140-20147.

Nicotra L, Loram LC, Watkins LR, Hutchinson MR (2012) Toll-like receptors in chronic pain. Exp Neurol 234:316-329.

Obata K, Katsura H, Miyoshi K, Kondo T, Yamanaka H, Kobayashi K, Dai Y, Fukuoka T, Akira S, Noguchi K (2008) Toll-like receptor 3 contributes to spinal glial activation and tactile allodynia after nerve injury. J Neurochem 105:2249-2259.

Ochoa-Cortes F, Ramos-Lomas T, Miranda-Morales M, Spreadbury I, Ibeakanma C, Barajas-Lopez C, Vanner S (2010) Bacterial cell products signal to mouse colonic nociceptive dorsal root ganglia neurons. Am J Physiol Gastrointest Liver Physiol 299: G723-G732.

Ohara K, Shimizu K, Matsuura S, Ogiso B, Omagari D, Asano M, Tsuboi Y, Shinoda M, Iwata K (2013) Toll-like receptor 4 signaling in trigeminal ganglion neurons contributes tongue-referred pain associated with tooth pulp inflammation. J Neuroinflamm 10:139.

Ohto U, Miyake K, Shimizu T (2011) Crystal structures of mouse and human RP105/MD-1 complexes reveal unique dimer organization of the toll-like receptor family. J Mol Biol 413:815-825.

Okubo M, Yamanaka H, Kobayashi K, Kanda H, Dai Y, Noguchi K (2012) Up-regulation of platelet-activating factor synthases and its receptor in spinal cord contribute to development of neuropathic pain following peripheral nerve injury. Mol Pain 8:8.

Opree A, Kress M (2000) Involvement of the proinflammatory cytokines tumor necrosis factor-alpha, IL-1 beta, and IL- 6 but not IL-8 in the development of heat hyperalgesia: effects on heatevoked calcitonin gene-related peptide release from rat skin. J Neurosci 20:6289-6293.

Park C-K, Xu Z-Z, Berta T, Han Q, Chen G, Liu X-J, Ji R-R (2014) Extracellular MicroRNAs activate nociceptor neurons to elicit pain via TLR7 and TRPA1. Neuron 82:47-54.

Qi J, Buzas K, Fan H, Cohen JI, Wang K, Mont E, Klinman D, Oppenheim JJ, Howard OMZ (2011) Painful pathways induced by TLR stimulation of dorsal root ganglion neurons. J Immunol 186:6417-6426.

Raghavendra V, Tanga FY, DeLeo JA (2004) Complete Freunds adjuvant-induced peripheral inflammation evokes glial activation and proinflammatory cytokine expression in the CNS. Eur $\mathrm{J}$ Neurosci 20:467-473.

Ren K, Dubner R (2010) Interactions between the immune and nervous systems in pain. Nat Med 16:1267-1276.

Schmid B, Finnen MJ, Harwood JL, Jackson SK (2003) Acylation of lysophosphatidylcholine plays a key role in the response of monocytes to lipopolysaccharide. Eur J Biochem 270:2782-2788.

Shindou H, Shimizu T (2009) Acyl-CoA:lysophospholipid acyltransferases. J Biol Chem 284:1-5.

Shindou H, Ishii S, Yamamoto M, Takeda K, Akira S, Shimizu T (2005) Priming effect of lipopolysaccharide on acetyl-coenzyme A:lyso-platelet-activating factor acetyltransferase is MyD88 and TRIF independent. J Immunol 175:1177-1183.
Shindou H, Hishikawa D, Nakanishi H, Harayama T, Ishii S, Taguchi R, Shimizu T (2007) A single enzyme catalyzes both plateletactivating factor production and membrane biogenesis of inflammatory cells. Cloning and characterization of acetyl-CoA: LYSO-PAF acetyltransferase. J Biol Chem 282:6532-6539.

Sommer C, Kress M (2004) Recent findings on how proinflammatory cytokines cause pain: peripheral mechanisms in inflammatory and neuropathic hyperalgesia. Neurosci Lett 361:184-187.

Stulnig TM, Huber J, Leitinger N, Imre EM, Angelisova P, Nowotny P, WaldhausI W (2001) Polyunsaturated eicosapentaenoic acid displaces proteins from membrane rafts by altering raft lipid composition. J Biol Chem 276:37335-37340.

Tanga FY, Nutile-McMenemy N, DeLeo JA (2005) The CNS role of Toll-like receptor 4 in innate neuroimmunity and painful neuropathy. Proc Natl Acad Sci U S A 102:5856-5861.

Triantafilou M, Lepper PM, Olden R, Dias IS, Triantafilou K (2011) Location, location, location: is membrane partitioning everything when it comes to innate immune activation? Mediators Inflamm 2011:186093.

Triantafilou M, Miyake K, Golenbock DT, Triantafilou K (2002) Mediators of innate immune recognition of bacteria concentrate in lipid rafts and facilitate lipopolysaccharide-induced cell activation. J Cell Sci 115:2603-2611.

Tse KH, Chow KBS, Leung WK, Wong YH, Wise H (2014a) Lipopolysaccharide differentially modulates expression of cytokines and cyclooxygenases in dorsal root ganglion cells via Toll-like receptor-4 dependent pathways. Neuroscience 267:241-251.

Tse KH, Chow KBS, Leung WK, Wong YH, Wise H (2014b) Primary sensory neurons regulate Toll-like receptor-4-dependent activity of glial cells in dorsal root ganglia. Neuroscience 279:10-22.

Uceyler N, Schafers M, Sommer C (2009) Mode of action of cytokines on nociceptive neurons. Exp Brain Res 196:67-78.

Vindis B, Gaspersic R, Skaleric U, Kovacic U (2014) Toll-like receptor 4 expression in trigeminal neurons is increased during ligatureinduced periodontitis in rats. J Periodontol 85:170-177.

Visintin A, Mazzoni A, Spitzer JA, Segal DM (2001) Secreted MD-2 is a large polymeric protein that efficiently confers lipopolysaccharide sensitivity to Toll-like receptor 4. Proc Natl Acad Sci U S A 98:12156-12161.

Vulchanova L, Riedl MS, Shuster SJ, Buell G, Surprenant A, North RA, Elde R (1997) Immunohistochemical study of the P2X2 and $\mathrm{P} 2 \mathrm{X} 3$ receptor subunits in rat and monkey sensory neurons and their central terminals. Neuropharmacology 36:1229-1242.

Wadachi R, Hargreaves KM (2006) Trigeminal nociceptors express TLR-4 and CD14: a mechanism for pain due to infection. J Dent Res 85:49-53.

Wu FX, Bian JJ, Miao XR, Huang SD, Xu XW, Gong DJ, Sun YM, Lu ZJ, Yu WF (2010) Intrathecal siRNA against Toll-like receptor 4 reduces nociception in a rat model of neuropathic pain. Int $\mathrm{J}$ Med Sci 7:251-259.

Zhang XC, Kainz V, Burstein R, Levy D (2011) Tumor necrosis factoralpha induces sensitization of meningeal nociceptors mediated via local COX and p38 MAP kinase actions. Pain 152:140-149.

Zhao XH, Zhang T (2015) The up-regulation of spinal Toll-like receptor 4 in rats with inflammatory pain induced by complete Freund's adjuvant. Brain Res Bull 111:97-103. 